\title{
The old versus the new: which do you keep in postoperative Crohn's disease?
}

\author{
Paulo Gustavo Kotze ${ }^{1,2}$, Christopher $\mathrm{Ma}^{1}$, Miguel Regueiro ${ }^{3}$, Remo Panaccione ${ }^{1}$ \\ ${ }^{1}$ Inflammatory Bowel Disease Unit, Division of Gastroenterology and Hepatology, University of Calgary, Calgary, Canada, ${ }^{2}$ Inflammatory \\ Bowel Disease Outpatient Clinics, Colorectal Surgery Unit, Catholic University of Paraná, Curitiba, Brazil, ${ }^{3}$ Inflammatory Bowel Disease Unit, \\ Division of Gastroenterology, Hepatology and Nutrition, University of Pittsburgh, Pittsburgh, PA, USA
}

It was with great interest that we read the paper entitled "Efficacy of restarting anti-tumor necrosis factor $\alpha$ agents after surgery in patients with Crohn's disease," recently published in Intestinal Research. ${ }^{1}$ In a retrospective analysis, the authors compared endoscopic recurrence rates between the strategies of restarting the same preoperative anti-tumor necrosis factor (anti-TNF) therapy versus initiating these agents in naïve patients, right after ileocolonic resections. They found that patients with pre-operative anti-TNF that maintained the same therapy postoperatively had higher rates of endoscopic recurrence as compared to those that were first exposed to these agents after surgery (OR, 28.1; 95\% CI, 3.08-7.22). They also found that low albumin and the presence of residual disease in other sites were also associated to higher recurrence rates.

The management of postoperative recurrence in CD has evolved over the years, mostly with the utilization of clinical features which identify those with higher risk of recurrence such as smoking, abdominal penetrating disease and previous resections, among others. ${ }^{2}$ This, in combination with postoperative colonoscopy 6 to 12 months after surgery to identify early disease recurrence, can lead to optimization of therapy, reduction of recurrence rates and subsequent reduction of symptoms, complications and need for further surgery. ${ }^{3}$

The strategy of initiating a new biological agent after ileo-

Received November 23, 2017. Revised November 27, 2017.

Accepted November 27, 2017.

Correspondence to Paulo Gustavo Kotze, Inflammatory Bowel Disease Outpatient Clinics, Colorectal Surgery Unit, Catholic University of Paraná, Rua Bruno Filgueira, 269 CJ. 1205, Curitiba 80240-220, Brazil. Tel: +55-413243-0033, Fax: +55-41-3243-0033, E-mail: pgkotze@hotmail.com colonic resections in CD was never adequately studied in a comparative way. This emphasizes the study by the distinguished Japanese colleagues, who for the first time compared the strategy of postoperative biologics in patients previously exposed to these agents as compared to individuals that were naïve to biological therapy. The difficult decision of initiating a naïve patient on biological therapy after surgery with no residual disease still remains controversial. ${ }^{4}$ We believe that patient stratification according to risk factors for recurrence is key to define the best postoperative strategy. Clearly, in the aforementioned study, patients on the restart group had characteristics of more severe disease, such as higher rates of younger patients, more patients on preoperative corticosteroids and immunomodulators, perianal disease and longer disease duration until initiation of antiTNF and until surgery. These features per se can justify that higher rates of recurrence should be expected in the restart group as compared to the naïve patients.

The ideal scenario in patients with preoperative biologics would be to measure serum levels and antibodies immediately before surgery. This would potentially elucidate the reason for surgery in the setting of biologics, like immunogenicity with secondary loss of response versus primary failure of the biologic with adequate drug levels. In this latter group, there would still need to be information on the timing of biologic start vis a vis surgery. That is, patients who initiate biologics in the setting of a complication and then require surgery are probably not true non-responders of biologics, rather patients who inevitably required surgery and "the damage is too far gone for biologic response."

Therapeutic drug monitoring (TDM) would allow the

๑ Copyright 2018. Korean Association for the Study of Intestinal Diseases. All rights reserved.

This is an Open Access article distributed under the terms of the Creative Commons Attribution Non-Commercial License (http://creativecommons.org/licenses/by-nc/4.0)

which permits unrestricted non-commercial use, distribution, and reproduction in any medium, provided the original work is properly cited. 
decision of continuing the same agent in the same dose, in a higher dose or of switching agents, even for a different mechanism of action. TDM theoretically would assist decisionmaking in what to do with biological agents after surgery, but there is a significant lack of studies exploring this strategy in the surgical field. ${ }^{5}$

Thus, despite the expected findings of the study by Hiraoka et al., ${ }^{1}$ that naïve patients using an anti-TNF agent right after surgery may have lower recurrence rates, we believe that mainly in patients with preoperative use of biologics, a prospective study of the best postoperative strategy could be warranted, based on TDM. If patients had positive antibodies, a switch to another agent would then be justified. In patients with low serum levels and no antibodies, one would argue if dose optimization with the same agent could be used, mostly in a different status after surgery, with a reduced inflammatory burden. Would the indication for surgery mean failure to the biologic itself? Without the use of TDM to determine immunogenicity and secondary loss of response versus primary failure this would remain in the field of speculation. The analysis of the postoperative specimen, with definition and quantification of fibrosis in the resected bowel may also play a role in decision-making.

Despite all the discussion that surrounds postoperative biological therapy in CD patients, we congratulate the authors for this innovative comparison and for outlining the limitations of their study in a clear way. As patients submitted to medical therapy that are naïve to biologics tend to have higher response and remission rates in the presence of active disease, the same seems to occur after surgical induced remission, but more studies in the field are needed.

\section{FINANCIAL SUPPORT}

The authors received no financial support for the research, authorship, and/or publication of this article.

\section{CONFLICT OF INTEREST}

P.G.K. has received speaking and consultancy honoraria from Abbvie, Janssen, Pfizer, Takeda and UCB. M.R. has served as a consultant for Abbott, Axcan, Centocor, Elan,
Procter \& Gamble, Salix, Shire, Takeda and UCB. R.P. has received research/educational support from AbbVie, Abbott, Ferring, Janssen, Schering-Plough, Centocor, Millennium, Elan, Procter \& Gamble, and Bristol-Myers Squibb. He has served as a consultant for AbbVie, Abbott, Amgen, Aptalis, AstraZeneca, Baxter, Eisai, Ferring, Janssen, Merck, ScheringPlough, Shire, Centocor, Elan, GlaxoSmithKline, UCB, Pfizer, Bristol-Myers Squibb, Warner Chilcott, Takeda, Cubist, Celgene, Gilead Sciences, and Takeda. R.P. has also participated on speaker's bureaus for AbbVie, AstraZeneca, Janssen, Schering-Plough, Shire, Ferring, Centocor, Elan, Prometheus, Warner Chilcott, and Takeda. He has attended Advisory Boards for AbbVie, Abbott, Amgen, Aptalis, AstraZeneca, Baxter, Eisai, Ferring, Genentech, Janssen, Merck, ScheringPlough, Shire, Centocor, Elan, GlaxoSmithKline, UCB, Pfizer, Bristol-Myers Squibb, Warner Chilcott, Takeda, Cubist, Celgene, and Salix.

\section{AUTHOR CONTRIBUTION}

P.G.K., C.M., M.R., and R.P. drafted the article, gave equal important intellectual content and reviewed and approved the final version.

\section{REFERENCES}

1. Hiraoka S, Takashima S, Kondo Y, et al. Efficacy of restarting anti-tumor necrosis factor alpha agents after surgery in patients with Crohn's disease. Intest Res 2018;16:75-82.

2. Kotze PG, Yamamoto T, Damião AO. Postoperative approach for Crohn's disease: the right therapy to the right patient [published online ahead of pirnt November 1, 2015]. Curr Drug Targets. doi: 10.2174/1389450116666151102094922.

3. De Cruz P, Kamm MA, Hamilton AL, et al. Crohn's disease management after intestinal resection: a randomised trial. Lancet 2015;385:1406-1417.

4. Regueiro M, Feagan BG, Zou B, et al. Infliximab reduces endoscopic, but not clinical, recurrence of Crohn's disease after ileocolonic resection. Gastroenterology 2016;150:1568-1578.

5. Papamichael K, Cheifetz AS. Use of anti-TNF drug levels to optimise patient management. Frontline Gastroenterol 2016;7:289300. 